\title{
A Survey of Correlation between Professional Identity and Clinical Competency of Psychiatric Nurses
}

\author{
Jamileh Mohtashami ${ }^{*}$, Hanieh Rahnama², Farahnaz Farzinfard ${ }^{3}$, Atefeh Talebi ${ }^{4}$, \\ Foroozan Atashzadeh-Shoorideh ${ }^{5}$, Mahdie Ghalenoee ${ }^{1}$ \\ ${ }^{1}$ Department of Psychiatric Nursing, School of Nursing and Midwifery, Shahid Beheshti University of Medical \\ Sciences, Tehran, Iran \\ ${ }^{2}$ Shahid Beheshti University of Medical Sciences, Tehran, Iran \\ ${ }^{3}$ Department of Community Health Nursing, School of Nursing and Midwifery, Shahid Beheshti University of \\ Medical Sciences, Tehran, Iran \\ ${ }^{4}$ Department of Biostatistics, School of Paramedical Sciences, Shahid Beheshti University of Medical Sciences, \\ Tehran, Iran \\ ${ }^{5}$ Department of Nursing Management, Nursing and Midwifery School, Shahid Beheshti University of Medical \\ Sciences, Tehran, Iran \\ Email: ${ }^{*}$ mohtashami@sbmu.ac.ir, $\underline{f}$ atashzadeh@sbmu.ac.ir
}

Received 5 July 2015; accepted 15 September 2015; published 18 September 2015

Copyright (C) 2015 by authors and Scientific Research Publishing Inc.

This work is licensed under the Creative Commons Attribution International License (CC BY).

http://creativecommons.org/licenses/by/4.0/

c) (†) Open Access

\begin{abstract}
Introduction: Clinical competency and knowledge of the effective factors are of critical importance in nursing. Competency, self-esteem, and self-knowledge are achievable through professional identity. Employees' participation in and attachment to their professional role is contingent considerably upon their professional identity. In light of this, the present study is aimed at determining correlation between professional identity and clinical competence of the nurses working in psychiatric wards of the hospitals affiliated with Tehran-based medical sciences universities. Methodology: This correlative study was conducted on 125 nurses working in psychiatric wards of Tehran-based hospitals affiliated with medical sciences universities. Data gathering tool of the study was a researcher-designed questionnaire to collect demographic, clinical competency, and professional identity data of the participants. For data analyzing, Statistical Package for the Social Sciences (SPSS) version 18 was used. Findings: The results showed $91.2 \%$ of the participants evaluated their professional identity at good $(47.2 \%)$ and very good $(44 \%)$ levels; and $78.2 \%$ evaluated their clinical competency at very good level. The results also indicated positive and significant relationship between professional identity and clinical competency $(r=0.32, p=0.001)$. In
\end{abstract}

\footnotetext{
${ }^{*}$ Corresponding author.
}

How to cite this paper: Mohtashami, J., Rahnama, H., Farzinfard, F., Talebi, A., Atashzadeh-Shoorideh, F. and Ghalenoee, M. (2015) A Survey of Correlation between Professional Identity and Clinical Competency of Psychiatric Nurses. Open Journal of Nursing, 5, 765-772. http://dx.doi.org/10.4236/ojn.2015.59080 
addition, none of the demographical variables were related to professional identity and clinical competency. Conclusion: There is positive relationship between clinical competency and professional identity, which means that development of positive attitudes regarding the psychiatric nursing can lead to higher clinical competency of the participants. The findings of the study highlighted the weight and role of positive attitude regarding the professional identity. It could result in increase of clinical competency and deserved attention of hospital's managers.

\section{Keywords}

Clinical Competency, Professional Identity, Psychiatric Nursing

\section{Introduction}

Intense competitive environment and technological changes impose ever-increasing pressure on organizations to improve performance of their workforce. This puts more emphasis on competency in the competitive environment [1]. Competency is an indispensable part of nursing [2], and the principle of profession of nursing [3]. It refers to a set of traits and characteristics that are needed for increasing performance in a profession [4].

Clinical competency of nurses is a critical issue [5] and improving or keeping it is a main challenge in the way of nursing management [6]; or in other words, it is the paramount goal of nursing programs [7]. Among the concerns that importance of the clinical competency lies in are rapid changes of health surveying systems, necessity of safe and affordable services; public informing works regarding health issues and consequently increase of expectations of service takers; desire to recruit more skillful staff by health service providers bodies [8]; and changes in roles and tasks of the nurse, which make it a complicated profession [9]. One may claim that guaranteeing quality of health services and ensuring clinical competency of nurses are of the main concerns of health systems and of top priorities of nursing programs [10].

Increase of specialization and complicacy have led the field of psychological health to develop into an independent field of nursing; at the same time challenges in the way of this profession is growing [11]. Zare et al. examined the challenges and solutions in the fields of psychiatric nursing in Iran and showed that while the psychiatric nurses are expected to provide quality services to the patients, the nurses must be provided with decent environment and organizational structure. These nurses should be equipped with special skills and competency based on characteristics of the society of service takers [12]. On the other hand, there are concerns among the experts about quality of mental health curriculums and programs. Any problem and shortcoming in the nursing program surely will result in notable effects in quality of services provided by the graduates. Keeping and developing competency is a task of professional mental health nurses [11]. Unfortunately, there is a small body of literature on psychological health nursing. Thereby, there is a need for more and deeper studies in this field [13].

Self-esteem and self-evaluation are outcomes of professional identity [14]. Professional identity is the unique perception of a nurse of their job [15] so that it is a main area of identity and of high importance in psychological definitions and viewpoints [16].

Dynamic and positive professional identity that has its roots in one's choice can lead to personal, social, and professional evolution [17]. Nursing is one of the most critical professions in health sector and the nurses preferably must have accepted their roles before entering this profession [18]. They are expected to work based on common values that represent their commitment and allegiance to their profession and the society [19]. Therefore, the nursing staff shall have enough knowledge regarding their profession [14]. Results of other studies have showed that psychiatric nurses do not take their job as a profession [20]. Another study showed that the nurses have wrong attitudes regarding their task and many of them see nursing as a job rather than a profession. Several studies in Iran and the Middle East have shown that nursing was not considered as a profession even by the nurses [18].

Assessment of personal characteristics of those in the profession of health services and surveys of probable relationship of such characteristics with performance are novel and growing approaches [21]. There is a paucity of surveys of professional identity and clinical competency of nurses in Iran and given the special condition of psychiatric nursing in the country (unclear professional task definition, lack of enough expert psychiatric nurses, 
lack of psychological health standard, absence of clear and transparent explanations, and overlapping tasks) the authors conducted the present study in an attempt to determine correlation between professional identity and clinical competency of the nurses in psychiatric wards of the hospitals affiliated with Tehran-based medical sciences universities.

\section{Methodology}

The study is a correlative descriptive work to survey correlation between professional identity and clinical competency of the nurses working in psychiatric wards of the hospitals affiliated with Tehran-Based medical sciences universities. Study population was comprised of all nurses working in psychiatric wards of Tehranbased hospitals affiliated with Tehran Medical Science University, and Shahid Beheshti University of Medical Sciences, who expressed their interest to take part in the study. Sampling method was census and 125 nurses participated in the study. A researcher-designed questionnaire was used for data gathering. The questionnaire is comprised of three sections: demographical information, clinical competency, and professional identity. Section one was on personal information of the nurse such as age, gender, marital status and the like. Clinical competency measurement tool, with 36 statements, was used in the section two. The nurses were asked to state frequency of using specific skills based on Likert's five-point scale ("never" = not using the skill and "always" = frequently using the skill). Maximum and minimum possible scores were 36 and 180 respectively. Participants who obtained $0 \%-25 \%$ of the maximum score (36 - 72) were at low level or weak, $25 \%$ - $50 \%$ of the maximum score $(73-108)$ were at moderate level, $50 \%-75 \%$ of the maximum score $(109-144)$ were at good level, and $75 \%-100 \%$ of the maximum score $(145-180)$ were at very good level. The third section of the questionnaire was on measuring professional identity of psychiatric nursing profession including 42 statements that asked the participants to express their viewpoint as to the professional identity of psychiatric nursing based on Likert's five-point scale (completely disagree,..., completely agree). Maximum and minimum scores were 42 and 210 respectively. Nurses who obtained $0 \%-25 \%$ of the maximum score (42 - 84) were at low level or weak, $25 \%$ $50 \%$ of the maximum score (85 - 126) were at moderate level, 50\% - 75\% of the maximum score (127 - 168) were at good and $75 \%-100 \%$ of the maximum score $(169-210)$ were at very good level.

Facial and content validity of the questionnaire were confirmed. So that the questionnaire was provided to 15 faculty board members of Faculty of Nursing and Midwifery, Shahid Beheshti University of Medical Sciences, and the nurses in psychiatric wards to rate facial and content validity of the questionnaire. The questionnaire was modified based on the feedbacks. Regarding reliability of the questionnaire, Cronbach alpha was obtained based on a pretest with 20 participants. With minimum level of reliability of $70 \%$, Cronbach alpha for clinical competency and professional identity questionnaires were obtained $92.5 \%$ and $89.3 \%$ respectively, and alpha value of the whole questionnaire was obtained 92.5\%. The collected data were analyzed in SPSS 18. All moral issues were observed; for instance, a letter of recommendation was secured from the universities and handed over to the authorities of the hospitals, the objectives of the study were clarified to the participants and confidentiality of their information was observed.

\section{Findings}

The study was conducted with participation of 125 nurses of psychiatric wards. Majority of the nurses were women (52.8\%), married (81.63\%), holders of bachelors' degree (90.4\%). In addition, majority of the participants had life time employment (48.8\% limited-term employment, 20.8\% contractual, 5.6\% temporary, and 4.8\% other arrangements), and were official employees (88.8\% nurse, and $11.2 \%$ head nurse). Moreover, majority of the participants were at age range 30 to 39 with average age of 35.4. Total work experience and experience as psychiatric nurse of majority of the participants were 10 and 2 years respectively. Average work experience and average work experience and experience as psychiatric nurse were 11.32 and 8.01 years respectively (Table 1).

The results showed that professional identity point ranged from 42 to 210 and mean point of professional identity was 158.40 . Majority of the nurses were at good level as to professional identity ( $47.2 \%$ good, $44 \%$ very good, $7.2 \%$ moderate, and $1.6 \%$ weak) (Table 2 ).

Total clinical competency point ranged from 36 to 180 and mean point of clinical competency was 153.36. Majority of the nurses were at very good level as to professional identity $(78.4 \%$ very good, $20.8 \%$ good, and $0.8 \%$ moderate, and $0 \%$ weak). Clinical competency is compromised from two sections: General and specific competencies (Table 3). 
Table 1. Demographical information.

\begin{tabular}{|c|c|c|c|}
\hline \multicolumn{2}{|c|}{ Variable } & \multirow{2}{*}{$\begin{array}{c}\text { Frequency } \\
66\end{array}$} & \multirow{2}{*}{$\begin{array}{c}\text { Percent } \\
52.8\end{array}$} \\
\hline & $\mathrm{F}$ & & \\
\hline Gender & M & 59 & 47.2 \\
\hline \multirow{7}{*}{ Age } & Total & 125 & 100 \\
\hline & $20-29$ & 24 & 19.2 \\
\hline & $30-39$ & 65 & 52 \\
\hline & $40-49$ & 34 & 27.2 \\
\hline & $50<$ & 2 & 1.6 \\
\hline & Average & \multicolumn{2}{|c|}{35.4} \\
\hline & SD & \multicolumn{2}{|c|}{6.36} \\
\hline \multirow{5}{*}{ Marital status } & Married & 102 & 81.6 \\
\hline & Unmarried & 19 & 15.2 \\
\hline & Divorced & 2 & 1.6 \\
\hline & Widow & 2 & 1.6 \\
\hline & Total & 125 & 100 \\
\hline \multirow{5}{*}{ Nursing experience (years) } & $2-10$ & 67 & 53.6 \\
\hline & $11-20$ & 42 & 33.6 \\
\hline & $21-30$ & 16 & 12.8 \\
\hline & Average & \multicolumn{2}{|c|}{11.32} \\
\hline & SD & \multicolumn{2}{|c|}{6.65} \\
\hline \multirow{5}{*}{$\begin{array}{l}\text { Experience in psychology ward } \\
\text { (years) }\end{array}$} & $2-10$ & 93 & 74.4 \\
\hline & $11-20$ & 28 & 22.4 \\
\hline & $21-30$ & 4 & 3.2 \\
\hline & Average & \multicolumn{2}{|c|}{8.01} \\
\hline & SD & \multicolumn{2}{|c|}{5.71} \\
\hline \multirow{3}{*}{ Position } & Nurse & 111 & 88.8 \\
\hline & Head nurse & 14 & 11.2 \\
\hline & Total & 125 & 100 \\
\hline \multirow{4}{*}{ Employment } & Life time & 86 & 48.8 \\
\hline & Other arrangement & 6 & 4.8 \\
\hline & Contractual & 26 & 20.8 \\
\hline & Temporary & 7 & 5.6 \\
\hline \multirow{2}{*}{ Education } & BSc & 113 & 90.4 \\
\hline & MSc & 12 & 9.6 \\
\hline
\end{tabular}

Table 2. Professional identity.

\begin{tabular}{ccccc}
\hline Professional identity & Number & Percent & Mean & Standard Deviation \\
\hline Weak $(42-84)$ & 2 & 1.6 & & \\
Moderate $(85-126)$ & 9 & 7.2 & 158.40 & \\
Good $(127-168)$ & 59 & 47.2 & \\
Very Good $(169-210)$ & 55 & 44 & \\
Total & 125 & 100 & \\
\hline
\end{tabular}


Table 3. Mean and standard deviation of clinical competency issues.

\begin{tabular}{cccccc}
\hline Clinical Competency Issues & Scores Range & Mean & Standard Deviation & Minimum & Maximum \\
\hline General & $8-45$ & 33.92 & 3.64 & 22 & 40 \\
Specific & $28-140$ & 119.43 & 11.49 & 81 & 140 \\
Total & $36-180$ & 153.36 & 14.24 & 105 & 180 \\
\hline
\end{tabular}

The Pearson's Correlation test showed positive and significant correlations (p-value $=0.001$, correlation coefficient 0.319 ) between professional identity and clinical competency of psychiatric nursing (Table 4). There was no significant relationship between professional identity/clinical competency and demographical variables (Table 5).

\section{Discussion}

Correlation between clinical competency and professional identity of psychiatric nurses in the hospitals affiliated with Universities of Medical Sciences at Tehran in 2014 was examined. The results showed positive and significant relationship between clinical competency and professional identity of the participants.

Majority of the participants (81.6\%) were married, and this figure in Ebrahimi et al. was 76.3\% [22]. On the other hand, 78.8 of nurses participated in Rezaei et al. were unmarried [23]. Thus, the present study is more consistent with Ebrahimi et al. [22]. Majority of the participants (53.6\%) had work experience between 2 and 10 years and only $12.8 \%$ of the participants had work experience more than 21 years (average work experience $=$ 11.31; standard deviation =6.65). Bahraini et al. reported the average work experience of the participants was equal with 7.98 (standard deviation 7.02) [24]; this figure in Habibzadeh et al. [25] and Karami Monaghi et al. [26] was 8.4 and 9 respectively. Comparing the results, work experience of the nurses in psychology wards in this study was higher than those of other studies.

Majority of the participants had Bachelors’ degree (90.4\%); likewise, majority of participants in Ebrahimi et al. [22] and Bahreini et al. [27] had bachelors' degree-89.9\% and 95.26\% respectively.

Mean point of the participants regarding professional identity was 158.40 with maximum and minimum points of 42 and 210 respectively. Majority of the participants reported their professional identity was at good level (47.2\% good, $44 \%$ very good, $7.2 \%$ moderate, $1.6 \%$ weak). Pilevarzade et al. reported that $58 \%$ of the nurses had good professional identity [14]. None of the demographical variables had significant relationship with professional identity, which is consistent with Pilevarzade et al. [14].

Moreover, Borjian Borjeni et al. studied attitudes of nursing graduates between 1995 and 2005 regarding their profession and concluded that $69.28 \%$ of the participants had positive attitudes. They came to conclusion that the majority of the nurses had managed to stand the stress, problems, shortages, and low income of their profession because of their interest and the nature of their job and the opportunity to serve the society [28]. Their results are consistent with this study.

Nikbahkt Nasrabadi et al. stated that a large number of nurses and nursing students did not have good attitude toward their profession and took their profession only as a job [29]. Variety of studies in Iran and other countries have shown that nursing is not considered as a profession even among nurses. Crowford et al. showed that some of psychiatric nurses had doubts about their job [20]. Their results are inconsistent with our results. Considerable inconsistency of the results obtained by different works signals the need for carrying out more extensive studies. Difference between study populations also explains parts of the differences. Our study population was mainly constituted by holders of bachelors' degrees in general nursing and highly experienced psychiatric nurses.

Mean point of clinical competency of the nurses was 153.36, with minimum and maximum points of 36 and 180 respectively. Majority of the nurses believed they were at very good level concerning clinical competency (78.4\% very good, 20.8\% good, 0.8 moderate, 0\% weak). Karimi Monaghi et al. [26] and Bahreini et al. [27] reported that the majority of the participants expressed that their clinical competency was at good level. Habibzadeh et al. reported that 63.2\% of the nurses had good and high clinical competency [25]; and Ghelje et al. concluded that $82.9 \%$ of the nurses reported their clinical competency was at expectable level and beyond [9]. Hatam Gouya consistently argued that $60.5 \%$ of the participants had very good clinical competency [21]. Results of the present study regarding clinical competency of psychiatric nurses seem reasonable, as being host of seriously mentally ill patients from all over of the country puts the nurses in unpredictable and complicated situ- 
Table 4. Correlation between clinical competency issues and professional identity.

\begin{tabular}{ccccccc}
\hline \multirow{2}{*}{$\begin{array}{c}\text { Clinical } \\
\text { Competency } \\
\text { Issues }\end{array}$} & $\begin{array}{c}\text { Specific } \\
\text { Correlation } \\
\text { coefficient }\end{array}$ & p-value & $\begin{array}{c}\text { Correlation } \\
\text { Coefficient }\end{array}$ & p-Value & $\begin{array}{c}\text { Clinical Competency Total } \\
\text { Coefrelation } \\
\text { Coefficient }\end{array}$ & p-Value \\
\hline $\begin{array}{c}\text { Professional } \\
\text { Identity }\end{array}$ & 0.301 & $0 / 001$ & 0.329 & 0.00 & 0.319 & 0.00 \\
\hline
\end{tabular}

Table 5. Correlation between clinical competency issues, professional identity and demographic characteristics.

\begin{tabular}{ccc}
\hline Variable & Professional & Clinical \\
Identity & Competency & Test Results \\
\hline \multirow{2}{*}{ Sex } & $\mathrm{Z}=-0.069$ & $\mathrm{t}=1.251$ \\
& $\mathrm{P}=0.94$ & $\mathrm{P}=0.21$ \\
Age & Spearman $=0.034$ & $\mathrm{Pearson}=0.149$ \\
& $\mathrm{P}=0.70$ & $\mathrm{P}=0.09$ \\
Marital Status & $\mathrm{X} 2=1.886$ & $\mathrm{~F}=1.403$ \\
& $\mathrm{P}=0.59$ & $\mathrm{P}=0.24$ \\
\hline
\end{tabular}

ations, which is an opportunity for the nurses to polish their skills. It appears also that effective educational system and in-service training courses are effective factors in development of clinical competency of the participants. Furthermore, total and related work experience of the nurses (11.32 and 8.01 years respectively) further explain high clinical competency of the participants. In fact, more experienced nurses are better in adapting to different situations and expectedly feel higher competency. Benner's model also showed that competency is achievable after long-term experience in a profession.

We found no significant relationship between clinical competency and demographical variables. Ebrahimi et al. found no significant relationship between general/marital statuses and clinical competency [22]. Habibzadeh et al. found no significant difference between employment condition, education level, gender, and age on one hand and mean clinical competency on the other hand [25]. Bahreini et al. showed in their study that there was no significant relationship between age and work experience on one hand and clinical competency on the other hand [30]. Habibzadeh et al. found significant relationship between experience and mean clinical competency; so that the higher work experience, the higher the clinical competency [25]. Ebrahimi et al. reported significant and negative correlation between clinical competency and work experience so that increase of experience led to decrease of clinical competency [22]. The results also indicated that there was a positive and significant relationship between professional competency and clinical competency. It appears that being more competent gives the nurses more positive attitude toward their profession. As to clinical competency, the results were based on self-statement and there is room to question reliability of the results in this regard. Taking this limitation into account, the authors recommend using alternative ways to measure clinical competency such as assessment by colleagues.

\section{Conclusion}

The results showed that professional identity and clinical competency of the psychiatric nurses were at good and very good levels respectively. Therefore, improvement of positive attitudes toward psychiatric nursing among the nurses will result in higher clinical competency. The results highlighted importance of paying more attention to positive attitudes toward psychiatric nursing.

\section{Acknowledgements}

This article is based on a MSc. dissertation conducted in Shahid Behshti University of Medical Sciences under research plan No.1393-1-86-13023. The permission for conducting the study was issued by ethical committee of the university on 18 Aug. 2014. The authors express their gratitude toward officials of the Faculty of Nursing and Midwifery, the university, the nurses and head nurses of the hospitals under study. 


\section{References}

[1] Hassanzadeh, M. (2005) Surveying the Effect of Cultural Organization on Empowering Employees. M.S.c Dissertation, Faculty of Humanities, Tarbiat Modares University, Tehran.

[2] Calman, L. (2006) Patients Views of Nurses’ Competence. Nurse Education Today, 26, 217-725. http://dx.doi.org/10.1016/j.nedt.2006.07.016

[3] Khosravinejad, M. (2012) Surveying the Effect of Services with Competency Based on Safety and Satisfaction with Nursing Services among Patients Hospitalized in Emergency Ward or Imam Khomeini Hospital, Khomein, Iran, 2012. M.Sc Dissertation, Tehran Medical Science University, Tehran.

[4] Ebadi, M. and Aliari, Sh. (2013) Training Based on Competency in Nursing. IRIRAN Army Nursing Faculty Journal, 1, 51-57.

[5] Dehghani, Z., et al. (2012) The Effect of Rethinking on Clinical Competency of Nursing Students. Payesh Quarterly, 12, 63-70.

[6] Jafari Golestan, N., Vananki, Z. and Memarian, R. (2007) Surveying the Relationship between Clinical Competency and Emotional Intelligence of the Nurses Working in Hospitals Affiliated with Kurdistan Medical Science University (2010). M.Sc. Dissertation, Shahid Beheshti Medical Science University, Tehran.

[7] Hakimzadeh, R., Karamdost, N., Memarian, R., Ghodrati, A. and Mirmosavi, J. (2002) Surveying Clinical Competency of Nursing Students Based on Self-Assessment. OfoghParastani Quartelry, 1, 17-25.

[8] Bagheri Nasami, M., Rafiei, F., Parvizi, S. and Esmaeili, R. (2008) Analyzing the Concept of Competency in Nursing, a Qualitative Research and Introducing a Hybrid Model. Mazandaran Medical Science University Journal, 18, 35-42.

[9] Ghalje, M., Gheljaie, F. and Mazlum, A. (2008) Correlation between Clinical Competency of Nursing and Their Satisfaction with the Nursing Services. Journal of Shahid Beheshti Medical Science University, 18, 12-19.

[10] Mohtashami, J., Salsali, M., Pazargadi, M. and Manochehri, H. (2013) Clinical Competency in Psychiatric Nursing Students: A Qualitative Study. Journal of Qualitative Research Health Sciences, 2, 261-276.

[11] Mohtashami, J. (2013) Designing a Model for Obtaining Clinical Competency among Students of Psychological Health Nurses. PhD Dissertation, Shahid Beheshti University of Medical Sciences, Tehran.

[12] Zare, K. (2012) Facing the Challenges and Building Solutions in Clinical Psychiatric Nursing in Iran: A Qualitative Study. Issues in Mental Health Nursing, 33, 697-706. http://dx.doi.org/10.3109/01612840.2012.698371

[13] Jahromi, M.K. (2013) Quality of Nurses' Performance of Intense Care Wards Based in Synergy Model. Iran Nursing Journal, 26, 74-83.

[14] Pilevarzadeh, M., Hosein Rezaei, H., Salari, S. and Nikian, Y. (2003) Surveying the Effect of Professional SelfKnowledge of Nursing Staff in the Hospitals Affiliated with Kerman Medical Science University. Journal of Shahdi Sadoughi Medical Sciences University of Yazd, 11, 57-60.

[15] Ohlen, J. and Segesten, K. (1998) The Professional Identity of the Nurse: Concept Analysis and Development. Journal of Advanced Nursing, 28, 720-727. http://dx.doi.org/10.1046/j.1365-2648.1998.00704.x

[16] Razavi, A. and Smaeili, M. (2010) Comparing Types of Professional Identity of Iranian Women. Women Studies, 4, 150-164.

[17] Cowin, L.S., Johnson, M., Wilson, I. and Borgese, K. (2013) The Psychometric Properties of Five Professional Identity Measures in a Sample of Nursing Students. Nurse Education Today, 33, 608-613. http://dx.doi.org/10.1016/j.nedt.2012.07.008

[18] Zamanzadeh, V., Aminiaei, N., Abdollahzadeh, F., Valizadeh, L., Seyed, B.M.S. and Fathiazar, S. (2009) Professional Attitudes of Nursing Teachers in Iran. Tabriz Nursing and Midwifery Journal, 15, 4-12.

[19] Price, S.L. (2009) Becoming a Nurse: A Meta-Study of Early Professional Socialization and Career Choice in Nursing. Journal of Advanced Nursing, 65, 9-11. http://dx.doi.org/10.1111/j.1365-2648.2008.04839.x

[20] Crowford, P., Brown, B. and Majomi, P. (2008) Professional Identity in Community Mental Health Nursing: A Thematic Analysis. International Journal of Nursing Studies, 45, 1055-1063. http://dx.doi.org/10.1016/j.ijnurstu.2007.05.005

[21] Goya, H.H. (2010) A Survey of Relation between Clinical Competency and Emotional Intelligence among Nurses Working in Hospitals Affiliated with Kordestan University of Medical Science in 2010. Master’s Dissertation, Shahid Beheshti University of Medical Sciences, Tehran.

[22] Ebrahimi, H., Hoseinzadeh, R., Zaghari, T.M., Hoseinzadeh, S. and Asghari, J.M. (2013) Clinical and Psychological Ability of Nurses and Its Correlation with Personal and Social Features. Health Improvement Management, 2, 30-38.

[23] Rezaei, A. (2013) Predicting Job Satisfaction of Nurses Based on Emotional Intelligence and Competency. Teb Jonoob Quarterly, 16, 128-137. 
[24] Bahreini, M., Ahmadi, F., Shahamat, Sh. and Behzadi, S. (2011) The Impact of Professional Portfolio on Nurses’ Clinical Competency. Journal of Strides in Development of Medical Education, 8, 107-114.

[25] Habibzadeh, H., Ghorbanzadeh, K., Khalkhali, H. and Mohammadpoor, Y. (2012) Surveying the Relationship between Quality of Working Life and Clinical Competency among Nurses. Ourumieh Nursing and Midwifery Two Monthly, 10, 332-339.

[26] Karimi, M.H., Gazrani, A., Vagheie, S., Gholami, H., Saleh, M.A.R. and Ashori, A. (2011) Relationship between SQ and Clinical Competency of Nursing. Sabzevar Medical Science and Health Services University Journal, 18, 132-139.

[27] Bahreini, M., Moattari, M., Akaberian, S.H. and Mirzaei, K. (2008) Determining Clinical Competency of Nurses Working in Universities Affiliated with Bushehr Medical Science University through Self-Assessment Method. Teb Jonoob Quarterly, 1, 69-75.

[28] Borjeni, A.B., Borjian, B.A., Raeisi, S., Borjian, B.S. and Mansori, S.H. (2010) A Survey of Satisfaction of Graduates of Nursing Faculty in Brojen regarding Their Field of Study. Journal of Hamdan Midwifery and Nursing Faculty, 18, 50-54.

[29] Nikbakht, N.A., Parsa, Y.Z., Seif, H. and Rasolzadeh, N. (2005) Professional Experiences at Entering Point to Clinical Nurses in Iran. Hayat Journal of Tehran Faculty of Nursing and Midwifery, 11, 5-18.

[30] Bahreini, M., Moattari, M., Kaveh, M.H. and Ahmadi, F. (2010) Comparing Clinical Competence among Nurses Working in Hospitals Affiliated with Shiraz and Boshehr Medical University: A Self-Assessment. Education in Medical Science Journal, 10, 101-110. 